\title{
A APRENDIZAGEM COMO DISCIPLINA DE DIÁLOGO: IMPLICAÇÕES CIENTÍFICAS E SOCIAIS
}

\author{
LEARNING AS A DIALOGUE DISCIPLINE: \\ SOCIAL AND SCIENTIFIC IMPLICATIONS
}

Mauro de Oliveira MAGALHÃES ${ }^{1}$

\begin{abstract}
RESUMO
No artigo são examinadas as bases históricas e filosóficas do pensamento ocidental para explicitar as crenças tácitas sobre a natureza do conhecimento que subjazem às interações sociais, com ênfase nos meios acadêmicos e científicos. São analisadas as conseqüências de idéias e atitudes presentes na tradição filosófica iniciada por Sócrates e Platão sobre o modo típico de pensar e resolver problemas em nossa cultura. A tarefa do conhecimento é descrita como uma disciplina de diálogo e construção coletiva.
\end{abstract}

Palavras-chave: ciência, aprendizagem, diálogo.

\begin{abstract}
The article examines the historical and philosophical background of occidental thinking in order to make explicit the tacit beliefs about the nature of knowledge behind the social interactions with emphasis on the academic and scientific fields. The consequences of the ideas and attitudes inherent in the philosophical tradition started by Socrates and Plato on the typical mode of thinking and problem-solving of our culture are analyzed. The task of knowing is described as a discipline of dialogue and social construction.
\end{abstract}

Key-words: science, learning, dialogue.

(1) Departamento de Psicologia da Universidade Luterana do Brasil (ULBRA)

Programa de Doutorado em Psicologia do Desenvolvimento (UFRGS)

Endereço para correspondência: Rua Sinimbú, 78 apto 303, bairro Petrópolis, Porto Alegre - RS telefones: (0XX51)

33886152 CEP 90470.470 - 98410034 E-mail: mauro.m@terra.com.br 


\section{INTRODUÇÃO}

Neste trabalho irei trazer algumas reflexões sobre o que considero serem os principais empecilhos para o estabelecimento de um diálogo e colaboração genuína entre indivíduos engajados na tarefa de adquirir e construir conhecimentos, tanto no nível dos conteúdos (informações) quanto no nível das habilidades (processos cognitivos) implicadas. Estes empecilhos são (a) a crença na idéia de verdade, (b) a utilização de uma estratégia estritamente argumentativa, crítica e defensiva para o debate das idéias e (c) a crença na autonomia do pensar individual. Estes fatores são complementares e constituem as bases do "equipamento" assumido tacitamente pela civilização ocidental como o método de pensar e resolver problemas.

\section{SOB O JUGO DA VERDADE}

\section{“Verdade baseia-se mais em 'O que é?'} do que em 'O que pode ser?'”

(De Bono, 1995, p. 62)

Para enfocar este tópico é necessário revisar historicamente o nascimento da filosofia grega e a sua influência sobre o pensamento ocidental. Após a guerra entre Grécia e Pérsia, de 490 a 470 a. C., Atenas transformou a sua marinha de guerra em uma frota mercante e tornou-se um porto movimentado, onde acediam tripulações das mais diversas culturas. Esta pluralidade em convívio gerou comparações, análise e reflexão. Durant (2000) sugeriu que os comerciantes tenham sido os primeiros filósofos pois "onde existem mil crenças, tendemos a nos tornar céticos em relação a todas elas" (p. 30). Estes homens prósperos puderam se dedicar à especulação e ao conhecimento sobre fenômenos da natureza até então revestidos de sacralidade religiosa e poderes sobrenaturais. A astronomia desenvolveu-se em resposta aos desafios da navegação e a matemática floresceu junto à complexidade das transações comerciais. "A magia e o credo foram lentamente cedendo lugar à ciência e ao controle; e nasceu a filosofia". (p.31)

Neste contexto surge o movimento dos sofistas, professores ambulantes de sabedoria que questionavam sem pudores os credos religiosos e políticos, submetendo-os ao escrutínio da razão. Por outro lado, eram céticos quanto à possibilidade de um conhecimento definitivo sobre qualquer coisa; o que Ihes importava era o saber pragmático. $\mathrm{Na}$ visão sofista, a verdade, tal como a percepção, é sempre uma questão de escolha. Protágoras argumentava que o mundo é o que cada pessoa escolheu perceber. A sua famosa frase "o homem é a medida de todas as coisas" é freqüentemente interpretada como uma versão individualista da verdade, pois, deste modo, todas as percepções são igualmente verdadeiras. Mas Protágoras não era um individualista, pois o seu objetivo maior era esclarecer que as desavenças entre os homens não serão resolvidas com base na verdade. (De Bono, 1990, 1995; Russell, 2001)

O pluralismo sofista abalou a fé religiosa do povo ateniense pois, nesta perspectiva, Deus existe para aqueles que acreditam em Deus. É claro que estas idéias encontravam adversários entre cidadãos e também entre filósofos como, por exemplo, Sócrates. Ora, a defesa de um critério de realidade baseado em idiossincrasias pessoais é caótica do ponto de vista normativo. E além disso, os sofistas ganhavam a vida como professores de retórica, ministrando aulas pagas de persuasão, isto é, ensinando métodos para mudar a visão de mundo alheia. Nas suas escolas, sustentavam que, com esses recursos, o argumento mais fraco poderá se tornar o mais forte. E por isso foram acusados pelos democratas de corromperem a juventude com ensinamentos subversivos.

Sócrates criticava duramente as práticas sofistas, mas, paradoxalmente, foi incluído 
neste grupo por muitos de seus contemporâneos. Talvez porque ambas as partes comungassem certos valores da aristocracia, que significa o governo dos melhores. O pensamento político dos sofistas, tal como Nietzche (1885/1978) viria a defender com o seu super-homem, considerava a moralidade uma invenção dos fracos para deter os fortes, e o poder como o desejo e a virtude suprema do homem. Por outro lado, Sócrates defendia que o bem era o conhecimento, e a ignorância, a fonte de todos os males. E sonhava com uma moralidade independente das doutrinas religiosas que amedrontavam os cidadãos. Para ele, o conhecimento era a fonte da moral, e uma sociedade é forte e justa se tiver em seu comando os homens mais sábios.

Este ataque à democracia refletia a tentativa de ascensão de uma minoria rica em Atenas, o partido oligárquico, que denunciava a democracia como uma impostura incompetente. Os sofistas foram então perseguidos e Sócrates obrigado a tomar cicuta. Diante disto, Platão, discípulo fervoroso de Sócrates, encheu-se "de tamanho desprezo pela democracia, tamanho ódio contra as massas, que nem mesmo a sua linhagem e sua criação aristocráticas haviam despertado nele; levando-o a uma decisão catônica de que a democracia precisava ser destruída". (Durant, 2000, p.39)

E assim, em A República, Platão sugeriu que a sociedade deveria ser governada por uma classe especial denominada "Guardiões". Estes cidadãos seriam selecionados e educados, desde a infância, com base em regras científicas que garantissem 0 desenvolvimento de sua competência administrativa e sabedoria para criar leis e governar. Esta era a utopia de Platão (Platão, trans. 1980b).

Platão desprezava o pluralismo democrático, pois estava convencido, e terminou por convencer as gerações subseqüentes de pensadores até os nossos dias, de que existe uma verdade única e eterna. O pluralismo e o ceticismo dos sofistas haviam feito a "percepção" dominante. A verdade era uma questão de ponto de vista, o que implica que as pessoas e o governo poderiam ser persuadidos pelos retóricos habilidosos. Platão não tolerava esta situação, pois estava preocupado com ordem, regras, verdade, fórmulas eternas e absolutas. E assim decidiu instaurar a ordem em nosso pensamento. E, historicamente, o pensamento ocidental assumiu que a verdade está em algum lugar. Resta-nos a tarefa de encontrá-la, pura, inteira e pronta a nos oferecer a dádiva de sua luz (De Bono, 1995; Glasersfeld, 2001).

$\mathrm{Na}$ famosa analogia platônica, ou socrática, as pessoas estão acorrentadas em uma caverna de tal maneira que podem observar somente sombras da verdade ou das formas essenciais (Platão, trans. 1980b). Não obstante, Platão argumentou que, quando somos filósofos, vemos as coisas à luz da verdade e da razão. Pois "os filósofos são aqueles que são capazes de atingir aquilo que se mantém sempre do mesmo modo". (Platão, trans. 2001, p.179). No diálogo do Fédon, esclareceu que a visão da verdade é possível ao homem porque Deus Ihe deixou esta herança latente através da alma; e que, por meio da eliminação das interferências corpóreas sobre o pensamento, o filósofo terá acesso às verdades sobre o mundo real. Neste sentido, o personagem Sócrates diz: “... o exercício próprio dos filósofos não é precisamente libertar a alma e afastá-la do corpo?" (Platão, trans. 1972, p.75). Glaserdfeld (2001) mostrou que o poder desta metáfora platônica, denominada o "mito da caverna", reside em apresentar uma situação poeticamente plausível, sem deixar claro que esta situação poderia ser descrita somente por um Deus, pois somente um Deus poderia saber o que há além da experiência humana. Pois, tal como Kant (1787/1978) escreveu, a razão humana pode alcançar somente o que ela mesma produziu de acordo com sua própria programação. 
Por outro lado, o relativismo sofista sobreviveu até nossos dias. Entre seus representantes estão os pensadores construtivistas, entre eles, Glasersfeld (2001) e Watzlavick (1981). O construtivismo postula que um organismo jamais será capaz de afirmar, verificar ou copiar a realidade; ele apenas poderá construir um modelo que se ajusta a ela. Estes autores se preocupam com o processo de "invenção" das realidades científicas, sociais e pessoais; considerando que a realidade pretensamente objetiva é sempre uma construção baseada em pressupostos tomados como fatos, mas que são apenas a conseqüência de um modo de se buscar a realidade. Neste sentido, cientistas no campo da física quântica levantam argumentos semelhantes (por exemplo, Bohm, 1965), pois asseveram que a ação de investigar, seus instrumentos e métodos, modifica a percepção do objeto do conhecimento; ou seja, o instrumento de observação e o objeto observado constituem-se na reciprocidade.

Esta participação mútua entre natureza e consciência $(B o h m, 1965)$ revela-se na interdependência entre as etapas do empreendimento científico, pois observa-se na articulação entre orientação teórica, método de investigação e "achados científicos" a construção de um argumento que defende uma idéia presente desde o início na atitude original do pesquisador. Numa visão sistêmica, constata-se a circularidade destes momentos, encadeados numa relação de cumplicidade, em que confirmação que se obtém da orientação teórica inicial deriva do método empregado, uma vez que o método (e a expectativa do investigador) cria em parte o que se descobre, da mesma maneira como o próprio cientista foi orientado em sua formação teórico-prática específica (Perls, Hefferline \& Goodman, 1965).

Ora, o objetivo fundamental da percepção é orientar o comportamento eficiente, e não reproduzir uma suposta realidade. Para a escola Gestalt, o percebido é uma figura que emerge de um fundo de possibilidades. Uma figura nítida e brilhante expressa a necessidade psicológica predominante no presente, organiza o campo organismo-meio e orienta o comportamento eficiente. Os psicólogos da Gestalt nos mostraram que os processos perceptivos tendem a se mover numa direção geral que subordina os ajustamentos particulares na busca da regularidade, da simplicidade e da estabilidade. Esta é a lei da pregnância, ou da "boa forma", que expressa o apetite estruturador da percepção em sua missão de organizar os processos psicológicos e orientar a conduta. Esta organização/ orientação será a melhor possível nas condições em que o organismo se encontra, será o seu esforço criativo para alcançar a posição mais confortável no seu contexto (Wertheimer, 1959). De acordo com Wertheimer (1959), o indivíduo deseja uma percepção "estruturalmente clara, na qual os itens encontrem seu lugar, função e papel claros, e não perturbem as linhas principais e a direção resultante de visão e ação". (p.244) E será possível discriminar se esta organização foi imposta ao caos ou emergiu do mesmo? Esta não é uma questão relevante se pensarmos sistemicamente, pois uma dada configuração perceptiva do campo organismo-meio emerge de uma necessidade de orientação para o comportamento (que, em última análise, é a busca da sobrevivência); e por isso impõe-se em primeiro plano, mesmo diante de alternativas (outras configurações possíveis), enquanto a excitação que a originou não tenha encontrado vazão suficiente, ou enquanto o organismo não seja confrontado com uma demanda mais urgente para sua sobrevivência (Perls, Hefferline \& Goodman, 1965). E, portanto, "o que chamamos conhecimento, num sentido amplo, é precisamente esta organização dinâmica do sistema organismo/entorno, enquanto the possibilita agir". (Assmann, 1995, p.3). Järvilehto (citado por Assmann, 1995, p.2) apresentou o cerne desta questão: 
Segundo a teoria do sistema unificado organismo/entorno, o surgimento das formas do conhecimento não está baseado em nenhum processo de transferência do entorno para dentro do organismo, porque não existem dois sistemas entre os quais pudesse ocorrer esta transferência. O conhecimento é a forma de existência do sistema (melhor: é o conhecimento que o faz existir nessa forma) e o conhecimento novo é criado quando se estão verificando mudanças na estrutura do sistema. $\mathrm{O}$ aumento do conhecimento representa uma ampliação do sistema e sua reorganização, o que torna possíveis novas formas de ação e novos resultados. Segue daí que o conhecimento como tal não está baseado em qualquer ação direta dos sentidos.

Bohm (1965) disse que o propósito da ciência não é o acúmulo de conhecimentos, mas a construção de mapas mentais orientadores da percepção e do comportamento, emergentes da parceria constante entre natureza e consciência. E, de fato, as lideranças científicas do século passado, de uma forma ou de outra, declararam que sua teorias eram somente modelos explicativos hipotéticos (Glaserdfeld, 2001). Portanto, tal como os sofistas, pensadores modernos preferem lidar com as realidades construídas e cambiantes, em vez de buscar uma verdade absoluta e imutável.

Este trabalho não pretende defender posições filosóficas sobre o conceito de verdade, mas sim apontar conseqüências que podem advir do apego irrefletido a determinado ponto de vista sobre a questão. Algumas destas conseqüências são abordadas no tópico a seguir.

\section{O MÉTODO SOCRÁTICO}

"Platão descobrira um novo prazer no jogo "dialético" de Sócrates; era um deleite ver o mestre esvaziar dogmas e ferretoar idéias preconcebidas com as aceradas pontas de suas perguntas. Platão entregara-se a esse desporto com o ardor com que se dedicara a outras lutas mais grosseiras". (Durant, 1959, p.33)

O que sabemos sobre o pensamento de Sócrates foi escrito por outros, principalmente por Platão. Platão expressou seu pensamento por meio de diálogos entre um "personagem" chamado Sócrates e outras pessoas. Este foi o veículo principal de nosso conhecimento do pensamento socrático, filtrado pela mente de Platão. De Bono (1995) resumiu a essência do método socrático como a busca incessante da verdade por meio de questionamento.

O método socrático pressupõe que o conhecimento esta aí, de modo absoluto, em algum lugar. Por outro lado, Sócrates também fez da ignorância uma virtude. Ele aparentemente foi informado pelo oráculo de Delfos que nenhum homem era mais sábio que Sócrates. Finalmente concluiu que isto era porque somente ele sabia de sua ignorância. Então ostentou sua ignorância e era quase orgulhoso de não ter conclusões após uma exploração de idéias sobre determinado tema. Ele considerava o seu papel como o de uma "mutuca" (como Sócrates chamava a si mesmo), provocando as pessoas a rever seus pensamentos na busca incessante de uma profundidade que se tornava tão mais inóspita e longínqua quanto mais buscava atingir o seu fundo. Era suficiente que seus estudantes começassem a questionar e a pensar; a conclusão não importava (Durant, 1959, 2000; De Bono, 1995).

A essência do método socrático era esclarecer erros, confusão e falsas premissas. Sócrates deleitava-se com a refutação. Diante de qualquer idéia oferecida, mesmo algo perfeitamente razoável, regozijava-se em dar um contra-exemplo, isto é, uma circunstância muito especial e, portanto, pouco provável, em que tal idéia não funcionaria. Seus con- 
tra-exemplos tornavam muito difícil chegar a alguma conclusão. De algum modo, pode ter sido a honestidade de Sócrates que não lhe permitiu delinear uma possível resposta e o fez esperar que a verdade se revelasse por si mesma, a despeito dos seus esforços para contrariar. Porém, as premissas de seu método de "diálogo" e o seu estilo de conviver foram perpetuados por Platão, tornando-se o método tradicional de pensar e conviver no ocidente (De Bono, 1995).

Ingenuamente pensamos que as coisas boas (como a verdade) já estão aí, obscurecidas pelas coisas ruins ou fora da vista, assim como muitos jardineiros pensam que é suficiente retirar as ervas daninhas para que as flores cresçam. A máxima socrática "conhece a ti mesmo" parece dizer que há um eu oculto a ser desvelado pela introspecção. Ou seja, a aparência esconde a essência. Ora, sob o véu da aparência encontraríamos somente vazio e o sentimento da falta de ser, um espaço a ser preenchido pelo esforço criativo de cada indivíduo. A fenomenologia existencial (por exemplo, Luijpen, 1973) e as correntes construtivistas contemporâneas (por exemplo, Glaserdfeld, 2001) concordam que a condição humana é também um encargo, pois os mundos humanos são construídos e não dados a priori. Talvez pudéssemos igualmente dizer "constrói a ti mesmo".

A obra do psicólogo E. De Bono (1971, 1995) salienta que a civilização ocidental desenvolveu uma estratégia de pensar baseada na premissa de que existem verdades únicas e absolutas, e que o esforço de conhecer deve ser direcionado à descoberta destas verdades. Esta crença considera que uma idéia é válida somente se resistir a uma bateria de críticas; se ela não se provar verdadeira em condições adversas, é rejeitada. Neste paradigma, constrói-se a modalidade característica de interação social em busca do conhecimento e da solução de problemas, qual seja, a modalidade adversarial ou argumentativa. Explica-se: o sujeito A apresenta seu argumento, o sujeito B educadamente diz: "aprecio suas idéias, mas a minha experiência leva a conclusões diferentes, deixe-me dizer...". À medida que cada lado defende seus argumentos, adota posturas cada vez mais veementes e congela-se em suas posições. E uma vez que a batalha foi lançada, ego e vitória são muito mais importantes do que explorar o tema ou objeto do conhecimento. Este é o roteiro típico das interações sociais bem intencionadas que buscam resolver problemas em todos os âmbitos da atividade humana e, muito freqüentemente, em contextos que pretendem apenas a participação e afiliação social em si mesmas (Senge, 1990; De Bono, 1995).

Isto é o resultado do que De Bono (1995) aponta como a valorização excessiva do pensamento crítico na cultura ocidental. Ambientes acadêmicos, principalmente, consideram o pensamento crítico como o mais alto nível de utilização do intelecto humano. Por que essa obsessão com a importância e a suficiência do pensamento crítico? Ora, é fácil observar que o sujeito interessado em aproximar-se, ser aceito ou admirado por seus pares deve dizer alguma coisa. Em conversas e encontros sociais, a forma mais fácil de contribuição é a negativa: "Sim, mas..."; "E sobre o perigo de... ?"; "Em tais circunstâncias isto não irá funcionar". Diante de qualquer idéia apresentada, não é difícil focalizar nos $5 \%$ que podem não funcionar ao invés dos 95\% que podem funcionar. Além disso, o criticismo é emocionalmente atrativo, na medida em que atacar uma idéia sugere superioridade à mesma. Nesse sentido, freqüentemente é uma cobertura legítima e útil para a inveja, como é comum no mundo acadêmico. A crítica traz um senso de realização e importância mesmo na ausência de uma contribuição positiva do sujeito, como no exemplo de muitos críticos de arte que se tornaram mais significativos do que os próprios artistas. Portanto, a grosso modo, pode-se dizer que o criticismo é uma forma leve de esforço intelectual. Se alguém 
pretende ser crítico, não é difícil encontrar um alvo. Por exemplo, escolhendo um esquema de referência diferente do arquiteto, você pode criticar a diferença entre a construção e o esquema de sua escolha. Se a construção é simples, você pode dizer que é simplória ou Bauhaus. Se a construção é elaborada, pode dizer que é fútil, ostensiva, vulgar e vitoriana. Se você não encontrou nada para dizer, diz que é derivativa (significando cópia de outro) ou repetitiva (significando que o arquiteto fez cópia de si próprio). Há um vasto repertório de observações extremamente fáceis de aplicar a qualquer coisa e mesmo assim soar profundo (De Bono, 1995).

E por fim, existe uma temor genuíno, e não completamente infundado, de que a ausência do criticismo leve o mundo ao caos. Assim como Sócrates sentiu que o criticismo era necessário para contrariar os retóricos Sofistas, nós ainda sentimos que as pessoas inteligentes têm o dever de guardar a sociedade contra idéias loucas ou novas. E a estratégia é criticar as idéias novas o mais tenazmente possível. Se elas sobreviverem, então possuem algum mérito. De Bono (1995) considerou que a estratégia socrática pode ter sido necessária em sua época e pode mesmo ser utilizada produtivamente na atualidade. Porém, tornou-se um hábito irrefletido e naturalizado como o método racional de resolução de problemas. O autor denominou o método socrático de argumentativo ou adversarial e esclareceu que não põe em questão a qualidade e o valor das idéias de Sócrates, mas argumentou ser contraproducente a utilização exclusiva e ingênua da estratégia de pensar fundada sobre suas premissas.

Nesse sentido, Senge (1996), em sua obra clássica sobre organizações que aprendem, salientou que a escola nos educa para nunca admitir que não sabemos a resposta, e a maioria das instituições de nossa sociedade reforça esta mentalidade, recompensando as pessoas pela competência em defender seus pontos de vista, e não pela capacidade de indagar abertamente sobre problemas complexos. O autor assevera que "mesmo quando nos sentimos inseguros ou ignorantes, aprendemos a nos proteger da dor de parecer inseguro ou ignorante. Este processo por si só bloqueia novas compreensões que possam nos ameaçar". (p.58) $E$, desse modo, adquirem-se habilidades de impedir a própria aprendizagem, tal como no funcionamento neurótico, o sujeito interrompe o contato com sua falta de autoconfiança e faz manobras para minimizar os efeitos de sua desvantagem, em vez de enfrentá-la e superála (Perls, Hefferline, Goodman, 1965). A incapacidade de aprender resulta então de manobras paradoxalmente inteligentes para evitar a percepção da ignorância, em lugar de aceitá-la e partir daí para a descoberta. Adquire-se o que Argyris (1990) denominou de incompetência hábil.

Em vista do que foi exposto, resta saber como podemos desenvolver uma nova disciplina de convívio que permita aos indivíduos o enriquecimento recíproco de suas capacidades de adquirir e criar conhecimentos, em vez de aprisioná-los em posições argumentativas. De Bono (1995) apresentou a sua proposta do pensamento paralelo ou pensamento lateral, termo que já foi incluído no dicionário Oxford de língua inglesa. Pensamento paralelo significa traçar idéias ou linhas de raciocínio paralelamente umas às outras. Não há choque, nem disputa, nem julgamentos verdadeiro/falso a priori. Os sujeitos devem buscar o interesse genuíno para uma autêntica exploração do tema. De Bono (1995) desenvolveu a técnica dos seis chapéus, a fim de instrumentalizar sua proposta. A técnica consiste em adotar seis chapéus metafóricos, de diferentes cores, que representam diferentes modos de pensamento em relação a uma temática ou questão determinada. Os pensadores em interação usam, simultaneamente, um mesmo chapéu de cada vez; e seguem, exclusivamente, o modo de pensar indicado pelo chapéu. $\mathrm{O}$ autor comenta que à primeira vista 
esta idéia pode parecer boba ou infantil, mas salienta a necessidade perceptual de um esquema concreto para fazer o método fácil de usar e lembrar. De maneira resumida, cada chapéu convida os participantes a adotarem os seguintes comportamentos intelectuais:

1. Chapéu branco: Focaliza o levantamento de informações sobre a questão. Qual informação é disponível? Como vamos conseguir a informação que precisamos? A qualidade da informação deve ser assinalada. Quando houver desacordos, isto pode ser conferido em outro momento.

2. Chapéu vermelho: Propõe a expressão de sentimentos e intuições. Não se espera uma justificativa lógica, pois a intuição pode estar baseada numa experiência complexa com a questão em foco, o que dificulta discriminar os fatores que a fundamentam, ao menos por enquanto. Evita que os sentimentos apareçam desordenadamente em outros momentos sob a forma de ataques ou apologias.

3. Chapéu preto: Solicita cautela, percepção de riscos e criticismo. Verifica se algo é coerente com a informação, experiência, objetivos, política, valores, ética, etc.

4. Chapéu amarelo: Indica a lógica positiva, os benefícios e valores. Os chapéus amarelo e preto demandam suporte lógico para as afirmações. $\mathrm{O}$ chapéu amarelo freqüentemente se mostra mais difícil do que o preto, pois somos mais treinados em perceber imperfeições, dificuldades e perigos.

5. Chapéu verde: O chapéu verde significa esforço criativo deliberado, isto é, a busca de alternativas e novas idéias. Para De Bono (1995), o exercício da possibilidade é responsável pelo progresso tecnológico do ocidente, não o sistema argumentativo, pois traz esquemas para perceber e arranjar idéias e informações em cursos inovadores de trabalho e criação.

6. Chapéu azul: É o chapéu para pensar sobre o pensamento, supervisionar e administrar o processo em andamento. Seria tipicamente utilizado pelo coordenador ou facilitador de um encontro.

O método dos seis chapéus usa o pensamento paralelo de três maneiras: (1) sob a vigência de determinado chapéu, cada pensador focaliza o tema, e não disputas com os colegas; (2) opiniões diferentes são postas em paralelo e aguardam apreciação posterior, se necessário; (3) os chapéus trazem direções paralelas para pensar, evitando choques entre estratégias e otimizando esforços. Por exemplo, o chapéu preto e o chapéu amarelo são esforços paralelos para pensar as dificuldades e os benefícios, respectivamente. Esta discriminação e direcionamento evita o bloqueio recíproco de cursos de pensamento a nível individual e grupal. O simbolismo dos chapéus permite que os participantes se indaguem mutuamente num jogo de papel de características lúdicas que previne manobras defensivas do ego e abre avenidas de exploração e criatividade que seriam impossíveis num contexto argumentativo (De Bono, 1985).

Propostas semelhantes foram apresentadas por Senge (1996) e Argyris (1990), que sugerem o treinamento de um equilíbrio entre processos de indagação e argumentação. A argumentação é a estratégia defensiva de pontos de vista ou opiniões anteriormente descrita, que permanece útil, pois as visões pessoais sempre existem, independente do sujeito acreditar que é o único correto ou não. Por outro lado, o processo de indagação significa a exposição, por cada participante, de sua linha de pensamento ao exame público, sem ocultar falhas ou raciocínios subjacentes. A diferença entre os dois processos, e o equilíbrio entre ambos, revela-se na forma 
como os sujeitos utilizam os dados, permitindo revelar-se ou não o raciocínio subjacente às suas abstrações. Quando há somente argumentação, os dados são utilizados seletivamente de modo a confirmar a posição adotada. Em contraste, na indagação cada participante deve esforçar-se por explicitar como construiu suas conclusões a partir de suas premissas e crenças fundamentais. Desta forma, há um convite à exploração recíproca entre os participantes sobre as potencialidades e falhas presentes nos esforços individuais.

O objetivo da indagação é encontrar as lacunas no processo de pensar, isto é, o que Senge (1996) denominou saltos de abstração. Explica-se: a rapidez dos processos cognitivos apóia-se em generalizações que simplificam uma quantidade de informações sob a forma de um conceito. Os conceitos podem ser descritos como rótulos lingüísticos que resumem e simplificam um conjunto complexo de experiências com base num denominador comum e, desde então, por razões práticas ou preguiça intelectual, passamos a tratar o rótulo abstraído da experiência como o próprio fato da experiência. Neste sentido, Bohm, Factor e Garret (2001) sugerem que precisamos de meios para desacelerar o processo de pensar, a fim de sermos capazes de observá-lo enquanto acontece e identificar as estruturas dinâmicas que o governam. Estas estruturas foram denominadas por Senge (1996) de modelos mentais, brevemente definidos como as imagens internas, profundamente arraigadas, sobre o funcionamento do mundo, que limitam os modos de pensar e agir a fórmulas conhecidas. Neste sentido, Senge (1996) propôs uma disciplina de aprendizagem que denominou "modelos mentais", que tem por objetivo trazer à tona, testar e aperfeiçoar essas imagens internas. Essa disciplina apóia-se no exercício combinado de habilidades interpessoais e habilidades de reflexão. As primeiras fundamentam-se no equilíbrio entre processos de indagação e argumentação na convivência grupal, e as segundas no treinamento para reconhecer e expor as premissas ou teorias implícitas que subjazem ao pensamento. $O$ autor esclarece que os problemas relacionados aos modelos mentais não residem em questões de certo e errado, pois todos os modelos são sempre simplificações, mas no fato de serem tácitos, isto é, indisponíveis para exame e reflexão. Portanto, o objetivo da disciplina dos "modelos mentais" não é encontrar a verdade, mas a melhor alternativa para lidar com questões específicas.

As idéias de Senge (1996) sobre aprendizagem grupal foram influenciadas pela obra do físico David Bohm. As idéias de Bohm (Bohm \& Nichol, 1996; Bohm, Factor \& Garret, 2001) revelam o caráter coletivo do pensamento e propõem o conceito de diálogo como uma prática de acesso e reflexão sobre as matrizes culturais reguladoras do pensamento humano. A crença de cada um na autonomia do seu processo de pensar mostra o quanto a noção de "eu" está hipertrofiada em nossa cultura. Esta hipertrofia faz com que vejamos a comunidade como apenas uma rede de compromissos contratuais, na qual realizamos transações que podem adicionar ou subtrair à grandiosidade do eu. Portanto, o autor vem oferecer subsídios para a superação dos empecilhos à convivência de aprendizagem gerados por essa visão solipsista do sujeito.

\section{OS DONOS DO PENSAMENTO: ATORES OU AUTORES}

Ficamos presos no teatro dos nossos pensamentos. A realidade pode mudar, mas o teatro continua. Operamos no teatro, definindo e resolvendo problemas, perdendo contato com o contexto maior que produz e dirige a cena (Senge, 1996).

Nas últimas décadas, muito se tem falado sobre o caráter coletivo do pensamento, isto é, o pensar individual não é uma mônada 
auto-suficiente que sobrevive no reduto de sua privacidade. A obra de Guattari e Rolnik (1986) nos esclareceu que, não obstante a pretensão de cada indivíduo em afirmar sua autonomia entitativa, as instância psíquicas que definem sua representação e vivência do mundo encontram-se em sistemas de conexão direta com as grandes máquinas produtivas, as grandes máquinas de controle social e de semiotização da subjetividade. O indivíduo é o terminal de sistemas de subjetivação, é um consumidor da subjetividade fabricada e em circulação nos conjuntos sociais.

Ou seja, os elementos constitutivos da subjetividade não estabelecem uma relação do tipo dentro/fora com um indivíduo recipiente de coisas exteriores. Pensadores contemporâneos argumentam que as distinções dentro/fora, natureza/cultura ou homem/máquina estão encontrando o limite de sua existência na vida cotidiana. A racionalidade está sofrendo crescentes ataques à sua imagem essencialista, uma vez já questionada pelo historicismo no advento da Modernidade, mostrando ser um efeito ecológico, que se sustenta no uso de tecnologias intelectuais variáveis no espaço e historicamente datadas (Lévy, 1993, Lissovsky, 1996, Pedro, 1996). Pierre Lévy (1993), em sua obra "As tecnologias da inteligência", propõe-se a "mostrar a quantidade de coisas e técnicas que habitam o inconsciente intelectual, até o ponto extremo no qual o sujeito do pensamento quase não se distingue mais (mas se distingue ainda) de um coletivo cosmopolita composto por dobras e volutas do qual cada parte é, por sua vez, misturada, marmoreada ou matizada de subjetividade branca ou rosa e de objetividade negra ou cinza" ( p.11).

Portanto, considerando-se que a racionalidade é uma construção coletiva e que a reflexão do indivíduo é um emergente de processos coletivos situados historicamente em determinada comunidade social e tecnológica (o que foi repetidamente exemplificado através do fenômeno do Zeitgeist), conclui-se que a aprendizagem e o acesso a níveis de reflexão mais intensos e radicais só ocorrerão por meio de disciplinas coletivas de convivência baseadas em um novo conjunto de premissas sobre a natureza do pensamento e do conhecimento. O pensamento do físico David Bohm (Bohm, Factor \& Garret, 2001; Bohm \& Nichol, 1996) sobre o diálogo destaca-se nessa busca. O autor considera o pensamento como um fenômeno sistêmico que surge de nossa forma de interação e discurso na dinâmica social. Senge (1996) resumiu a concepção de D. Bohm sobre o significado do diálogo:

No diálogo, um grupo explora questões difíceis e complexas de vários pontos de vista. Os indivíduos suspendem seus pressupostos embora os comuniquem livremente. O resultado é uma livre exploração que traz à tona a total profundidade da experiência e do pensamento das pessoas, e ainda assim pode ir além das suas visões individuais. (p.268)

Neste contexto de vulnerabilidade, o diálogo permite que o grupo aceda a um grande conjunto de significado comum, inacessível individualmente. Nas palavras dos autores:

O diálogo é um modo de observar, coletivamente, como valores e intenções ocultas podem controlar nosso comportamento, e como diferenças culturais não examinadas podem se chocar sem compreendermos o que está acontecendo. ... No diálogo, um grupo de pessoas pode explorar as pressuposições, crenças e sentimentos, individuais e coletivos, que sutilmente controlam as suas interações. (Bohm, Factor \& Garret, 2001, p.2)

O principal objetivo do diálogo é revelar a incoerência do pensamento tal como ele é geralmente praticado. O pensar é algo dado na experiência cotidiana, não temos consciência da programação que seguimos ao empreendermos a reflexão sobre determinado problema. No nível pré-reflexivo, assumimos 
que este é um procedimento natural tal como a respiração ou a coordenação de movimentos de nosso corpo. Bohm, Factor e Garret (2001) esclareceram que na execução motora temos a possibilidade da consciência do movimento enquanto este ocorre e, mais importante, podemos prestar atenção e controlar aspectos como velocidade, intensidade, ritmo, etc. Este não é o caso quando abordamos processos de pensamento. Não possuímos algo análogo à propriocepção enquanto pensamos; e por isso ignoramos os caminhos que inadvertidamente optamos por seguir em nosso raciocínio. O autor propõe o diálogo como o contexto em que tal "propriocepção do pensar" pode ser desenvolvida, em que coletivamente possamos trazer à tona as estruturas dinâmicas que o governam. Do contrário, estaremos presos a um programa de pensar que simplesmente segue em frente sem considerar as demandas da realidade, pois estabelece o seu próprio padrão de referência para resolver problemas, os quais, paradoxalmente, contribuiu para criar. Esta é a incoerência do pensamento, na terminologia de Bohm e Nichol (1996). Os autores propuseram algumas condições para a superação dessas incoerências por meio do diálogo, a saber:

a) Todos os participantes devem suspender seus pressupostos. Isso significa abdicar de premissas inegociáveis e aceitar que a base do pensamento sempre é um conjunto de crenças, que somente serão perniciosas se agirem na dimensão do esquecimento. É compreender que o pensamento é uma representação e não a realidade. Portanto, os participantes devem expor suas premissas ao exame público, superando a tendência a preservar suas verdades, e adotar o máximo de imparcialidade. A comparação entre pressupostos produz um esclarecimento mútuo das incoerências a que estamos submetidos, tanto como indivíduos quanto como uma comunidade. O contraste das perspectivas gera novas possibilidades que seriam inacessíveis individualmente.

b) Todos os participantes devem encarar uns aos outros como colegas. A vulnerabilidade gerada pela suspensão de pressupostos necessita de um clima de solidariedade e segurança para enfrentar o risco de colocar em cheque as próprias crenças. Os indivíduos colaboram num contexto de liberdade e não-julgamento, buscando o aspecto lúdico de experimentar novas idéias, examinando-as e testando-as. Este tipo de coleguismo assume gradativamente uma forma de participação na qual os envolvidos se sentem integrados num fluxo comum de significação.

c) Deve haver um facilitador que mantenha o contexto do diálogo. Senge (1996) observou que, na ausência de um facilitador, facilmente instala-se a modalidade argumentativa de interação, principalmente nas etapas iniciais da convivência em grupo. O facilitador deve identificar esses desvios e perguntar ao grupo se as condições descritas nos itens anteriores continuam sendo cumpridas. Ele não deve atuar como um especialista, mas devolver continuamente ao grupo a responsabilidade sobre o que ocorre, salientando a necessidade de expressar pressupostos implícitos. Devido à própria natureza do diálogo, 0 papel do facilitador perde relevância à medida que o grupo adquire mais habilidades de diálogo.

\section{CONSIDERAÇÕES FINAIS}

A necessidade de redefinir os objetivos de educação, no sentido de aquisição de habilidades cognitivas e atitudes em vez de 
um simples acúmulo de informações, já foi repetidamente constatada e defendida nas últimas décadas. Há quase 40 anos proliferam programas de capacitação cognitiva que têm por objetivo geral instrumentar os indivíduos com as mais variadas habilidades intelectuais. Tornou-se quase lugar comum dizer que o objetivo da educação deve ser de "aprender a aprender". Porém, a efetiva implementação desta idéia não tem sido tão freqüente (Pelletier, Bujold \& Noiseux, 1982).

Uma das razões para essa preocupação é a constatação cada vez mais radical da efemeridade do conhecimento. Ou seja, o que é válido hoje provavelmente não o será amanhã, portanto é mais vantajoso possuir um knowhow intelectual utilizável em situações novas e imprevisíveis do que reproduzir fórmulas memorizadas.

Por outro lado, observa-se que a constatação do caráter efêmero do conhecimento não é acompanhada por uma revisão de crenças e atitudes profundas sobre a questão. Verifica-se o contraste entre o que Argyris (1990) descreveu como teorias esposadas (no caso: "o saber é efêmero e relativo") e teorias em uso ("existe uma única resposta verdadeira, profunda e imutável"), isto é, a usual dissociação entre discurso e prática. Pois, junto a uma retórica construtivista, presenciamos o predomínio da estratégia argumentativa no convívio social voltado para a produção de conhecimento e para a solução dos problemas humanos.

Sobre este aspecto, escutamos muitos educadores argumentarem que ensinam os seus alunos a pensar e não somente a reproduzir. Porém, facilmente constatamos que, quando o dizem, querem dizer que o fazem quando estimulam o pensamento crítico em seus alunos. Ou seja, "aprender a aprender" tem sido traduzido na prática como "aprender a criticar e argumentar". Ora, o reconhecimento de que ensinar estratégias de pensar é mais proveitoso carrega a pergunta sobre quais estratégias ensinar. Quais instrumentos de pensar devem ser adquiridos para alcançar a capacidade de "aprender a aprender"? Considero que a resposta seria: tantos quantos possamos inventar.

Portanto, além de adquirir métodos de pensar, primeiramente é fundamental ter a capacidade de "pensar o pensamento", isto é, entender que o pensar não é um processo dado a partir da natureza, mas uma construção humana, um equipamento que utilizamos para resolver problemas. E, muitas vezes, podemos estar nos aperfeiçoando no método errado e cometendo equívocos com perfeição, pois não cogitamos a possibilidade de adotar outros equipamentos de pensar. Neste sentido, a tradição oriunda de Sócrates e Platão instalou-se como o método de pensar em si mesmo, e não como uma estratégia entre outras. Pensar o pensamento e aprender a reconhecer e escolher estratégias e modelos de realidade é o objetivo das propostas apresentadas por De Bono (1995) com o pensamento lateral, por Senge (1996) com as disciplinas de aprendizagem grupal e organizacional, e por Bohm, Factor e Garret (2001) com sua concepção de diálogo.

Por fim, tal como referido por Caon (2001), é urgente desenvolver não somente capacidades de aquisição de conhecimentos, mas também capacidades de convívio com pessoas. Penso que neste último aspecto observa-se uma deficiência tanto enraizada quanto pouco reconhecida e refletida em seus fundamentos. Neste trabalho busquei identificar alguns destes fundamentos. Sócrates e Platão nos ensinaram a ser profundos e buscar a razão última das coisas, a realidade pura e imutável a que somente os filósofos têm acesso. Nesta busca, perpetuou-se um método de pensar abusivamente crítico e autoritário e, portanto, belicoso do ponto de vista social. Em contraste, Protágoras advertiu que "as desavenças entre os homens não serão resolvidas com base na verdade", e, na minha opinião, esta é a lição que carecemos aprender. 


\section{REFERÊNCIAS}

ARGYRIS, C. (1990). Overcoming organizational defenses. Needham Heights: Allyn and Bacon.

ASSMANN, H. (1995). Alguns toques na questão: o que significa "aprender"? Coletâneas do programa de pós-graduação em educação, 1(1). Porto Alegre: UFRGS, Faculdade de Educação, Programa de Pós-graduação em Educação.

BOHM, D. (1965). The special theory of relativity. Nova York: Benjamin.

BOHM, D., Factor, D. , Garret, P. (2001). Dialogue - a proposal [On-line]. Disponível Internet: http://www.users.globalnet.co.uk/ -Imed/e-texts/bohm_dialogue.htm .

BOHM, D., Nichol, L.(1996). On dialogue. New York: Routledge.

CAON, J. L. (2001). Celebração ou incineração do professor convencional e do aluno velho? Palestra proferida no seminário interdisciplinar avançado do programa de pós-graduação em psicologia do desenvolvimento da UFRGS por ocasião da celebração do dia do professor, 15 de outubro, Porto Alegre - RS.

DE BONO, E. (1971). O mecanismo da mente. Petrópolis: Vozes.

DE BONO, E. (1985). Six thinking hats. New York: Little/Brown \& Co.

DE BONO, E. (1990). Lateral thinking: creativity step by step. New York: Harper \& Row.

DE BONO, E. (1995). Parallel thinking: from socratic to De Bono thinking. New York: Penguin Books.

DURANT, W. (1959). História da filosofia. São Paulo: Companhia Editora Nacional.

DURANT, W. (2000). A história da filosofia. Rio de Janeiro: Nova Cultural.

GLASERSFELD, E. V. (2001). Radical constructivism and teaching. Em http://
www.umass.edu/sri/vonGlasersfeld/ onlinepapers $/ \mathrm{html} / g$ geneva acesso em 10/11/2001.

GUATTARI, F., Rolnik, S. (1986). Micropolítica: cartografias do desejo. Rio de Janeiro: Vozes.

KANT, E. (1978). Crítica da razão pura. Coleção Grandes Mestres do Pensamento. São Paulo: Ed. Formar. (Originalmente publicado em 1787).

LÉVY, P. (1993). As tecnologias da inteligência: o futuro do pensamento na era da informática. Rio de Janeiro: Ed. 34.

LISSOVSKY, M. (1996). As retinas artificiais. Em M. T. D'amaral (org). Contemporaneidade e novas tecnologias. (pp. 27-52). Rio de Janeiro: Sette Letras.

LUIJPEN, W. (1973). Introdução à fenomenologia existencial. São Paulo: EPU.

NIETZCHE, F. (1978). Assim falava Zaratustra. Coleção Grandes Mestres do Pensamento. São Paulo: Ed. Formar. Originalmente publicado em 1885.

PEDRO, R.M.L. (1996). Cognição do híbrido. Em M. T. D'amaral (org). Contemporaneidade e novas Tecnologias. (pp. 53-76). Rio de Janeiro: Sette Letras.

PLATÃO (1972) Diálogos: Fédon - Sofista - Político. (J. Paleikat \& J. C. Costa, Trans.). São Paulo: Abril Cultural.

PLATÃO (1980a) Diálogos I: Mênon - Banquete - Fedro. (J. Paleikat \& J. C. Costa, Trans.). Rio de Janeiro: Edições de ouro/ Editora Tecnoprint.

PLATÃO (1980b) Diálogos III: A República. (J. Paleikat \& J. C. Costa, Trans.). Rio de Janeiro: Edições de ouro/ Editora Tecnoprint.

PLATÃo (2001) A República. (P. Nassetti, Trans.). São Paulo: Martin Claret. 
PELLeTIER, D., Noiseux, G. \& Bujold, C. (1982). Desenvolvimento vocacional e crescimento pessoal: enfoque operatório, Petrópolis: Vozes.

PERLS, F., Hefferline, R.F., Goodman, P. (1965). Gestalt therapy: excitement and growth in human personality. New York: Delta Book.

RUSSELL, B. (2001). História do pensamento ocidental. São Paulo: Ediouro.
SENGE, P. (1996). A Quinta disciplina: arte, teoria e prática das organizações de aprendizagem. São Paulo: Nova Cultural.

WATZLAWICK, P. (org.) (1981). La realidad inventada: como sabemos lo que creemos saber? Barcelona: Gedisa, 1990.

WERTHEIMER, M. (1959). Productive thinking. Nova York: Harper \& Brothers.

Recebido para publicação em 10 de junho de 2002 e aceito em 27 de janeiro de 2003. 